\title{
MAEDI-VISNA VÍRUS: PRODUÇÃO DE ANTÍGENO, ANÁLISE PROTÉICA E ANTIGÊNICA
}

\author{
M.A.C. Aragão ${ }^{1 *}$, R.R. Pinheiro ${ }^{2}$, A. Andriolii ${ }^{2}$, F.S.F. Alves ${ }^{2}$, A.A.F. Oliveira $^{3}$, M.F.S. Teixeira ${ }^{1}$ \\ ${ }^{1}$ Universidade Estadual do Ceará, Av. Paranjana, 1700, CEP 60740-903, Fortaleza, CE, Brasil. E-mail: \\ alzirac@hotmail.com
}

\section{RESUMO}

\begin{abstract}
A Maedi-Visna é uma doença persistente, progressiva e debilitante em ovinos causada por lentivírus que resulta primariamente em pneumonia intersticial e pode estar associada a mamite e encefalite. Este trabalho teve como objetivo produzir antígeno a partir do vírus Maedi-Visna total para utilização em ensaios imunoenzimáticos. Na produção do antígeno foram utilizados cultivos primários de células de membrana sinovial caprina, infectados com amostra padrão (MVVK1514). As suspensões virais foram tituladas e o antígeno semipurificado pela precipitação em PEG (polietilenoglicol) e ultracentrifugação. Foram realizadas eletroforese em gel de poliacrilamida (SDS-PAGE) e Western Blotting (WB). A SDS-PAGE de origem viral e do meio de cultivo resultou em várias bandas protéicas. No WB constatou-se a presença de sete proteínas imunogênicas de pesos moleculares aproximados de 16, 27, 35, 50, 42, 63 e 123 kDa. Destas, três proteínas (16, 27 e $50 \mathrm{kDa}$ ) apresentaram boa reação imunogênica. Otrabalho abre perspectivas da utilização de testes imunoenzimáticos com maior sensibilidade para lentivírus ovino.
\end{abstract}

PALAVRAS-CHAVE: Lentivirose, ovino, diagnóstico, proteínas.

\section{ABSTRACT}

MAEDI-VISNA VIRUS: ANTIGEN PRODUCTION, PROTEIN AND ANTIGENIC ANALYSIS. Maedi-Visna is a persistent, progressive and debilitating disease in sheep caused by lentivirus which results primarily in interstitial pneumonia and may be associated with mastitis and encephalitis. This study aimed to produce antigen from the Maedi-Visna virus for use in immunosorbent assay. The antigen was produced using secondary cultures of cells from sheep synovial membrane, infected with the standard sample (MVV-K1514). The suspensions were titered and the viral antigen was semipurified by precipitation in PEG (polyethylene) and ultracentrifugation. The isolates were then submitted to polyacrylamide gel electrophoresis (SDSPAGE) and the western blot (WB) technique. The SDS-PAGE of viral origin and of the culture medium resulted in several protein bands. The $\mathrm{WB}$ revealed the presence of 7 immunogenic proteins of approximate molecular weights of 16, 27, 35, 50, 42, 63 and $123 \mathrm{kDa}$. Of these, 3 proteins $(16,27$ and $50 \mathrm{kDa})$ showed good immunogenic reaction. This work opens up prospects of using enzyme immunoassay with greater sensitivity to lentivirus-infected sheep.

KEY WORDS: Lentivirose, sheep, diagnosis, proteins.

\section{INTRODUÇÃO}

A Maedi-Visna é uma infecção persistente de ovinos, causada por lentivírus, resultando primariamente em pneumonia intersticial, podendo apresentar mamite e encefalite associadas. Segundo McGuire et al. (1990), existem várias cepas deste lentivírus diferindo na virulência e antigenicidade. Várias pesquisas demonstram a caracterização de antígenos dos lentivírus (DAHLBERGet al.1981;DAviES et al., 1997).

Houwers et al. (1982) desenvolveram um ELISA para a detecção de anticorpos para o MVV com um antígeno parcialmente purificado, compararam com a imunodifusão em gel de agarose (IDGA) e o teste de fixação de complemento (FC), e verificaram que todas as amostras positivas na IDGA, FC ou ambas também foram positivas no ELISA. HOUWERS; SCHAAKE (1987)

\footnotetext{
${ }^{2}$ EMBRAPA Caprinos, Sobral, CE, Brasil.

${ }^{3}$ Universidade Federal Rural de Pernambuco, Recife, PE, Brasil.

*Programa de Pós em Ciência Veterinária.
} 
utilizaram anticorpos monoclonais para p27 do MVV num ELISA sanduíche de bloqueio com dois anticorpos ("double antibody sandwich blocking - DAS blocking") e os resultados foram comparados com aqueles obtidos na IDGA eno ELISA-i. A nova técnica, denominada de CTB-ELISA, foi altamente específica e tão sensível quanto IDGA e ELISA-i.

A eficiência dos programas sanitários de controle de lentivírus de pequenos ruminantes depende da sensibilidade e especificidade dos testes utilizados no diagnóstico inicial, da freqüência de sua utilização, no monitoramento sorológico das medidas implantadas e nos manejos utilizados no rebanho. Para realização periódica de testes sorológicos dos rebanhos, a técnica de IDGA é empregada mundialmente como método de triagem e monitoramento das fases iniciais de programas de controle mas, apesar da boa especificidade, a IDGA pode apresentar resultados falso-negativos (KNowles, 1997). Testes sorológicos com maior sensibilidade devem ser utilizados quando ocorrer redução substancial da quantidade de animais soropositivos, testados por IDGA e, ainda, quando a taxa de soroconversão no rebanho, apesar de baixa, for mantida (EMBRAPA, 1996). Segundo SCHROEDERet al. (1985), a IDGA não é muito sensível além do tempo de estima para sua realização (dependente do número de amostras) e leitura (em média de 48 a 72 horas), principalmente em grande quantidade de animais. Em decorrência deste aspecto, distintas modalidades de testes imunoenzimáticos têm sido desenvolvidas para a detecção de anticorpos contra lentivírus de pequenos ruminantes, utilizando antígenos nativos ou recombinantes (KNowles, 1997). Este trabalho teve como objetivo produzir antígeno para ensaios imunoenzimáticos preparado a partir do vírus Maedi-Visna total e analisá-lo quanto ao perfil protéico e antigênico.

\section{MATERIAL E MÉTODOS}

\section{Cultivo de células}

Para produção de suspensões e titulações do lentivírus ovino (LVO), foram utilizados cultivos primários de células de membrana sinovial caprina (MSC) obtida por " explant" a partir de cabrito (oriundo do rebanho comprovadamentenegativo aos LVPR, mantidonaEMBRAPA Caprinos) comprovadamente negativo para LVPR, seguido de sub-cultivos por tripsinização das células (PINHEIRO, 2001), totalizando um número limitado a 17 passagens.

\section{Vírus, titulação e suspensão viral}

Na produção da suspensão viral utilizou-se amostra padrão do vírus da Maedi-Visna -Cepa $\mathrm{K} 1514^{1}$ com título inicial de $10^{4,3}$ dose infectante em cultura de tecido/mL (TCID/mL). Monocamadas semicon fluentes (90 a 95\% de confluência) de Membrana Sinovial Caprina (MSC) ( $11^{\mathrm{a}}$ passagem), cultivadas em garrafas roller de $830 \mathrm{~cm}^{2}$ de superfície de cultivo, foram inoculadas, 72 a 96 horas após passagem, com $15 \mathrm{~mL}$ de suspensão viral contendo 200 doses formadora de sincício (DFS)/ $\mathrm{mL}$ diluída em meio essencial mínimo (MEM) sem soro fetal bovino (SFB). Após 60 minutos adicionaram-se $135 \mathrm{~mL}$ de MEM com $5 \%$ de SFB. As garrafas foram incubadas a $37^{\circ} \mathrm{C}$ em estufa $\left(5 \%\right.$ de $\left.\mathrm{CO}_{2}\right)$, sendo observadas diariamente para averiguar a evolução do processo. Coletou-se o sobrenadante semanalmente por três vezes ou até a destruição de $75 \%$ da monocamada. Os sobrenadantes coletados, bem como as garrafas contendo sobrenadante da última coleta, foram congeladas a $-80^{\circ} \mathrm{C}$ para posterior titulação e produção do antígeno. As suspensões virais foram tituladas em microplacas, por diluições decimais em MEM sem SFB, utilizando-se oito repetições por diluição. A cada $50 \mu \mathrm{L}$ da diluição da suspensão de células de MSC contendo 3,0 × $10^{4}$ células $/ \mathrm{cm}^{2}$ foi adicionado $50 \mu \mathrm{L}$ de vírus. Foram mantidos poços com controle positivo (células de MSC e LVO) e negativo (células de MSC e MEM). As microplacas foram incubadas em estufa a $37^{\circ} \mathrm{C}$ com $5 \%$ de $\mathrm{CO}_{2}$ durante 14 dias com observação diária do efeito citopático (ECP) característico (formação de sincícios). Após este período, a suspensão de células foi fixada em metanol e corada com cristal violeta a $0,1 \%$. O título, calculado segundo ReED; Muench (1938), definido como a recíproca da maior diluição que apresentou, 14 dias após inoculação, sincícios em $50 \%$ dos poços inoculados, correspondendo a uma DFS (CASTRO, 1998).

\section{Purificação do vírus e produção do antígeno}

Na produção do antígeno, os sobrenadantes das coletas iniciais e o conteúdo das garrafas mantidos congelados foram submetidos a dois ciclos de congelamento e descongelamento e então clarificados por centrifugação a $3.300 \mathrm{~g} \mathrm{em}$ rotor Sorvall GSA a $4^{\circ} \mathrm{C}$ por 20 minutos. A suspensão clarificada foi precipitada com PEG- 8000 a 40\%, até a concentração final de $8 \%$, por $18 \mathrm{~h} \mathrm{a} 4{ }^{\circ} \mathrm{C}$, sob lenta agitação, seguida de nova centrifugação a $4^{\circ} \mathrm{C}$ a $12.000 \mathrm{~g}$ em rotor Sorvall GSA por 60 min (ReIs; LeITE, 1994). O sedimento foi

\footnotetext{
${ }^{1}$ Amostra viral oriunda do Laboratoire Associé de Recherches sur les Petits Ruminants - INRA - ENVL - France.
} 
suspenso em TNE (10,0 mM Tris-HCl, $\mathrm{pH}$ 7,4; 10,0 $\mathrm{mM} \mathrm{NaCl} ; 1,0 \mathrm{mM}$ EDTA) na proporção de $10 \%$ do volume original da suspensão viral e ultracentrifugado em colchão de sacarose (25\% em TNE) a $32.500 \mathrm{~g}$ por $120 \mathrm{~min}$ a $4^{\circ} \mathrm{C}$ (Houwerset al., 1982). O sedimento foi suspenso em PBS $(0,05 \mathrm{M} ; 1,5 \mathrm{M} \mathrm{NaCl}$; pH7,4) contendo $0,20 \mathrm{mM}$ dephenylmethylsulphonyl fluoride (PMSF) na proporção de $0,5 \%$ do volume inicial.

\section{Dosagem de proteína,SDS-PAGE e Western Blotting (WB)}

A concentração de proteína total foi determinada segundo BRADFORD (1976) e o antígeno mantido a $-20^{\circ} \mathrm{C}$ até a realização dos ensaios laboratoriais. O antígeno purificado foi submetido a eletroforese em gel de poliacrilamida (SDS-PAGE) utilizando mini-gel ${ }^{2} \mathrm{com}$ $4 \%$ de gel de concentração e $12 \%$ de gel de separação, acompanhado com padrão broad-range (10 - 200 $\mathrm{kDa})^{3}$ (LAEMmi, 1970). O perfil eletroforético foi determinado nas amostras de antígeno diluídas em tampão de amostra (SDS 10\%; glicerol 20\%; azul de bromofenol $0,2 \% ; 0,5 \mathrm{M}$ Tris- $\mathrm{HCl}, \mathrm{pH} 6,8$ ) aquecendo a mistura a $100^{\circ} \mathrm{C}$ por 3 minutos. As proteínas do gel foram coradas usando azul de Comassie, segundo Harlon; LANE (1988).

No WB, as proteínas do antígeno, inicialmente separadas por SDS-PAGE, foram transferidas do gel para membrana de nitrocelulose ${ }^{4}(\mathrm{MN})$ através do trans-blot ${ }^{5}$ em tampão de transferência, por 60 minutos a 100 volts e $350 \mathrm{~mA}$. Após a transferência para $\mathrm{MN}$, as proteínas foram bloqueadas com solução de bloqueio (PBS Tween 0,3\%) por 60 minutos e lavadas com solução de lavagem (PBS Tween $0,05 \%)$ por três vezes, cinco minutos cada. O soro positivo do kit comercial ${ }^{6}$ para diagnóstico do Maedi-Visna foi diluído (1:50), adicionado as MN e incubado por 90 minutos a $37^{\circ} \mathrm{C}$. Em seguida as $\mathrm{MN}$ foram novamente lavadas, sendo colocado conjugado de coelho anti-IgG caprina marcado com diluído (1:1500) em PBS, por 60 minutos. Após lavagem com PBS Tween $0,05 \%$ por três vezes, cinco minutos cada, e com PBS, duas vezes, cinco minutos cada, a MN foi colocada em solução de DAB/4-Cloronapthol (solução A- 12 mg de
Diaminobenzidine em 12 mL de PBS, solução B- 5 $\mathrm{mg}$ de 4-Cloronapthol ${ }^{8}$ adicionado a $2 \mathrm{~mL}$ de metanol mais $10 \mathrm{~mL}$ de PBS), acrescentou-se $10 \mathrm{~mL}$ de $\mathrm{H}_{2} \mathrm{O}_{2}$ a $30 \%$ por aproximadamente 15 minutos ao abrigo da luz. A reação foi finalizada com a lavagem da MN com água destilada. Todas as etapas, com exceção da revelação, foram realizadas sob agitação.

\section{RESULTADOS}

A produção do antígeno do vírus total da MaediVisna resultou em volume de $2,0 \mathrm{~mL}$ apresentando a quantidade de proteína de $2,5 \mu \mathrm{g} / \mathrm{mL}$. Em eletroforese (Fig. 1) verificou-se várias bandas protéicas independente de ter se utilizado $5 \mu \mathrm{g}$ ou $10 \mu \mathrm{g}$ nas canaletas. As proteínas tinham pesos moleculares variando de $16 \mathrm{kDa}$ a $123 \mathrm{kDa}$.

No immunoblot (Fig. 2), quando utilizou-se uma quantidade de $10 \mu \mathrm{g}$ na canaleta, observou-se sete proteínas imunogênicas, com os pesos moleculares aproximados de 16, 27, 35, 50, 42, 63 e $123 \mathrm{kDa}$. Entretanto, as bandas de peso molecular aproximado de $16 \mathrm{k}$ Da e $27 \mathrm{kDa}$ foram as que apresentaram maior reação imunogênica, seguida pela proteína p50. As bandas de peso molecular de 35, 42, 63 e $123 \mathrm{kDa}$ também apresentaram uma boa reação imunológica (considerando-se as que apresentavam reação mais forte). Quando se utilizou soro negativo não se verificou bandas protéicas imunogênicas pela inexistência de ligações.

\section{DISCUSSÃO}

Na Quadro 1 estão listadas várias proteínas antigênicas encontradas em alguns trabalhos para o MVV. Avaliando as proteínas encontradas neste trabalho com as observadas por diversos autores encontramos uma similaridade com as seguintes proteínas virais: glicoproteínas- gp90, gp70 e gp38; ascore proteínas - p27, p19 e p14; bem como, o precursor viral Prgag55.

Segundo KWANG; GutLIP (1992) a glicoproteína transmembrânica (gp44) e a proteína do capsídeo

\footnotetext{
${ }^{2}$ Mini-Protean II Cell ${ }^{\circledast}$ - Bio-Rad.

${ }^{3}$ Broad-range 10-200kDa Protein Ladder. Gibco.

${ }^{4}$ Membrana de nitrocelulose Dura-blot ${ }^{\mathrm{tm}}$, com poro de $0,45 \mathrm{~mm}$.SIGMA.

${ }^{5}$ Trans-blot ${ }^{\circledR}$ - Bio-Rad.

${ }^{6}$ Caprine Arthritis-Encephalitis/Ovine Progressive Pneumonia Antibody Test Kit. Veterinary Diagnostic Technology,Inc ${ }^{\circledR}$ - USA.

73,3'-Diaminobenzidine (DAB) - Sigma.

${ }^{8} 4$-Cloro-1-Naphto - Sigma.
} 
(p27) são os principais determinantes antigênicos dos lentivírus ovinos, o que corrobora em partecom os achados neste trabalho, onde se verificou a presença da p27.

Muitos trabalhos têm sido realizados para determinar-se a nomenclatura em termos de peso molecular, glicosilação e quantidade dos polieptídeos (relatados entre10a 25 em vírus Maedi-Visna maduro) em lentivirus ovino. Além disso, três polipeptídeos gag foram descritos para este gênero de vírus em ovinos, p14, p16 (também designado como p15) e p25, considerada a principal proteína do capsídeo (também designada p26, p27, p28 e p30) (Torfasonet al., 1992).

A banda de 35kDa é um precursor (Pr35) que, de acordo com Sonigo et al. (1985), pode ser a gp39. A existência da gp44 (reportada como $44 \mathrm{kDa}, 45 \mathrm{kDa}$ ou 46kDa), a p50 (ou gp51), bem como a gp70, foi relatada por TORFASON et al. (1992). A p80 e a gp90 (reportada como gp92) foram descritas (HASSE; BARINGER, 1974; CHEEVERsetal.,1988). Um polipeptídeo fosforilado (gp90) pode, possivelmente, ser parte da transcriptase reversa. Relatam-se, também, a gp105

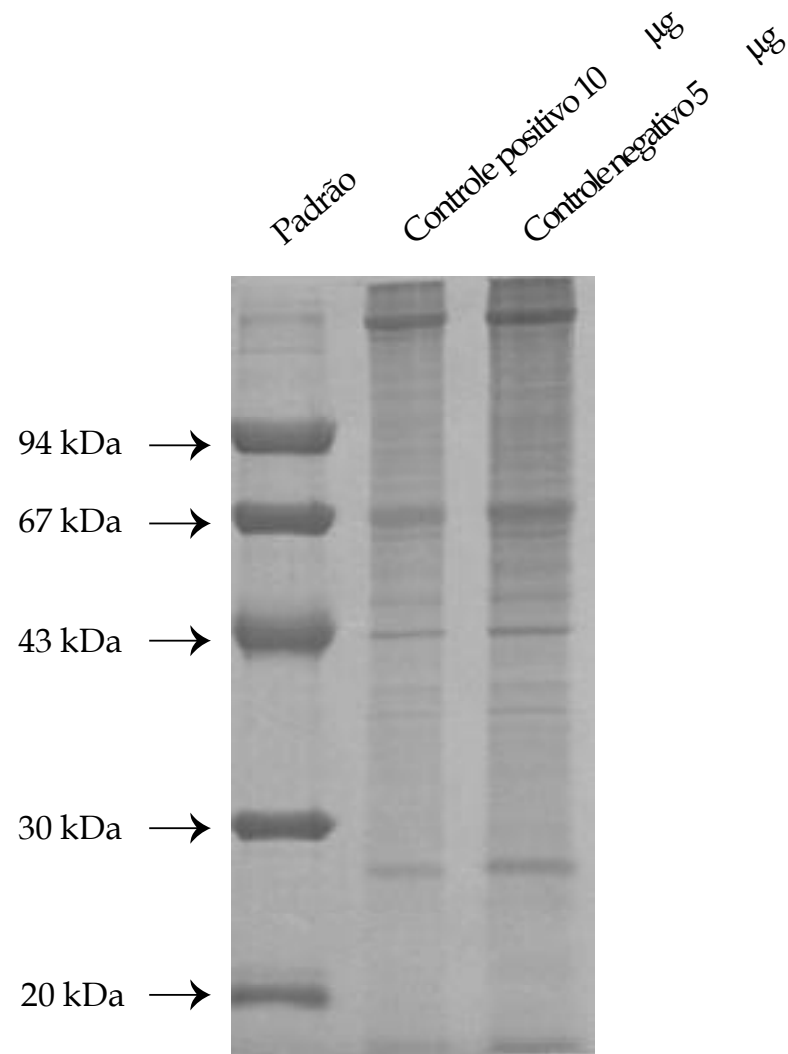

Fig. 1 - Eletroforese de antígeno do vírus da Maedi-Visna cepa K1514. e a gp135 (descrita como gp115, gp140 ou gp145). Fevereiro; Barros (2004) identificaram as proteínas relacionadas ao isolado P1OLV, tendo registrado a ocorrência da Pr55Gag, p16, p14, Pr160GagPol, p30, gp150, gp125 e gp 41. A proteína de peso molecular aproximado $123 \mathrm{kDa}$, detectada pelo immunoblot neste trabalho, está relacionada ao precursor Pr160GagPol. Com o lentivírus caprino (LVC) os relatos são semelhantes.

TORFAsOn et al. (1992) relataram que alguns antígenos, especialmente as glicoproteínas, são sensíveis ao tratamento sofrido na purificação. Relatam, também, que no início dos testes immunoblot e ELISA comerciais para o diagnóstico do lentivírus humano (HIV) os glicopolipeptídeos eram pobremente expressados, provavelmente devido à perda destes durante a preparação. OzYORUK et al. (2001) verificaram no immunoblot que anticorpos monoclonais reagiram com glicoproteína de superfície do vírus CAEV-63 seguidos de desnaturação somente na ausência de agente redutor, indicando que as pontes dissulfeto intramolecular foram essenciais para a integridade do epitopo.

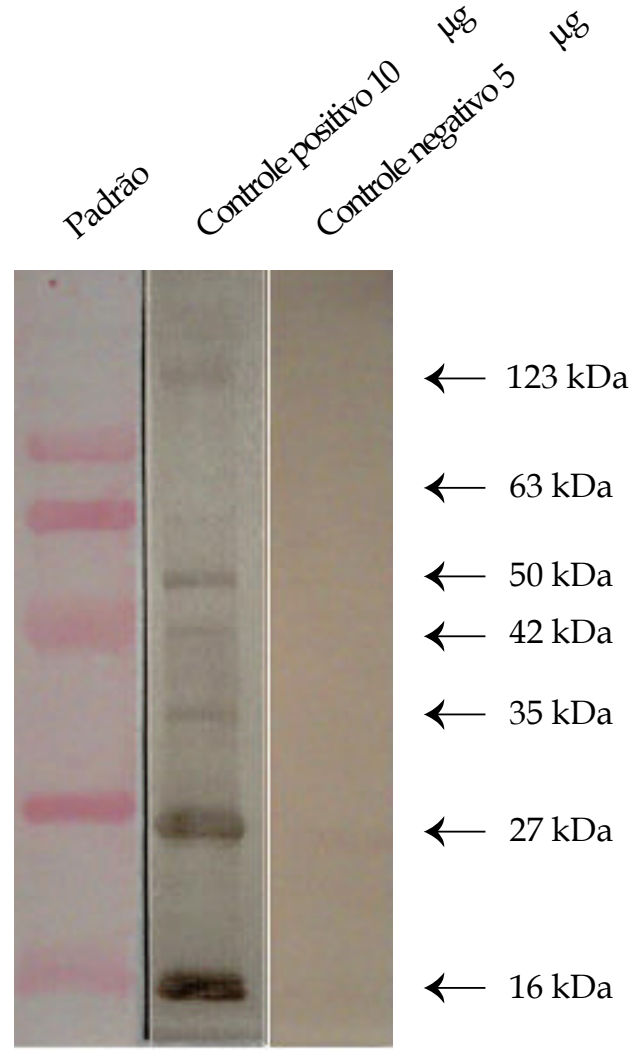

Fig. 2 - Immunoblotting do antígeno do vírus da MaediVisna. Verificou-se a presença de sete bandas com reação imunogênica sendo três mais reagentes com peso molecular aproximadamente de 16, 27 e $50 \mathrm{kDa}$. 
Quadro 1 - Polipeptídeos encontrados no MVV segundo vários autores.

\begin{tabular}{|llll|}
\hline Autores (ano) & Vírus & Teste & Proteínas encontradas (kDa) \\
\hline DAHLBERG et al. (1981) & CAEV & Imunoprecipitação & CAEV - gp155, gp140, p63, p51, p28, p17, p14 \\
& MVV & & MVV- gp155, gp135, gp105, p56, p46, p27, p15, \\
& & p13,5 & MVV-gp135, várias bandas (0-100kDa), p35, p25, \\
ToRfASOn et al. (1992) & MVV & Immunoblot & $\begin{array}{l}\text { p16, p14 } \\
\text { p14, p17, p25, gp46 }\end{array}$ \\
VAREA (2001) & MVV & Immunoblot & \\
\hline
\end{tabular}

\section{CONCLUSÃO}

As proteínas antigênicas encontradas neste trabalho, por já terem sido constatadas por outros autores, levam a perspectiva de sua utilização na produção de antígeno em testes diagnósticos. A presença de precursores, inclusive, permite a possibilidade do diagnóstico de proteínas imaturas. Assim, a identificação de proteínas existentes nos antígenos permitirá, inclusive, a utilização, ou mesmo o desenvolvimento, de técnicas de produção de antígeno que conservem ao máximo as proteínas virais.

\section{AGRADECIMENTOS}

À EMBRAPA Caprinos e ao Banco do Nordeste, pelo suporte técnico-financeiro na execução de todo o delineamento experimental; e à Fundação Cearense de Apoio à Pesquisa - FUNCAP pelo suporte financeiro na forma de bolsa.

\section{REFERÊNCIAS}

BRADFORD, M. A rapid and sensitive method for the quantiation of microgram quantities of protein utilizing the principle of protein-dye binding. Analytical Biochemistry, v.72, p.248-254, 1976.

CASTRO, R.S. Lentivirus de pequenos ruminantes: ensaios imunoenzimáticos, perfil sorológico e inferências filogenéticas. 1998. 132f. Tese (Doutorado em Ciência Veterinária) Escola de Veterinária, Universidade Federal de Minas Gerais, Belo Horizonte, 1998.

CHEEVERS, W.P.; McGUIRE, T.C. The lentiviruses: MAEDI/VISNA, Caprine Arthritis-encephalitis and Equine Infectious Anemia. Advances in Virus Research, v.34, p.189-215, 1988.

DAHLBERG, J.E.; GASKIN, J.M.; PERK, K. Morphological and immunological comparison of caprine arthritis encephalitis and ovine progressive pneumonia viruses. Journal of Virology, v.39, n.3, p.914919, 1981.
DAVIES, J.M.; ROBINSON, W.F.; CARNEGIE, P.R. Antibody reactivity to the transmembrane protein of the caprine arthritis encephalitis virus correlates with severity of arthritis: no evidence for the involvement of epitope mimicry. Veterinary Immunology and Immunopathology, v.60, p.131-147, 1997.

EMBRAPA. Relatório de Consultoria - Programa de Controle da Artrite Encefalite Caprina a Virus (PCAEV-II) (subprojeto $\mathrm{N}^{\mathrm{o}}$ 06.0.94.102-01). Sobral: Centro Nacional de Pesquisa de Caprinos, 1996. 110p.

FEVEREIRO, M.T.; BARROS, S.S. Caracterização biológica e molecular de um lentivírus de ovino isolado em Portugal. Revista Portuguesa de Ciência Veterinária, v.99, p.27-39, 2004.

HAASE, T.A.; BARINGER, J.R. The structural polypeptides of RNA slow viruses. Virology, v.57, p.238-250, 1974.

HARLON, E.; LANE, D. Antibodies: a laboratory manual. New York: Cold Spring Harbor Laboratory, 1988. 865p.

HOUWERS, D.J.; SCHAAKE, J. An improved ELISA for the detection of antibodies to ovine and caprine lentiviruses,employing monoclonal antibodies in a one-step assay. Jounal of Immunological Methods, v.98, p.151-154, 1987

HOUWERS, D.J.; GIELKENS, A.L.J.; JAN SCHAAKE, JUNIOR, J. An indirect enzyme-linked immunosorbent assay (ELISA) for the detection of antibodies to MAEDI-VISNA virus. Veterinary Microbiology, v.7, p.209-219, 1982.

KNOWLES, D.P. Laboratory diagnostic tests for Retrovirus infections of small ruminants. Veterinary clinics of North America: food animal practice, v.13, p.1-11, 1997.

KWANG, J.; CUTLIP, R.C. Analysis of antibody response to ovine lentivirus by using viral gene products expressed in a prokaryotic system. Biochemical and Biophysical Research Communications, v.188, p.20-27, 1992.

LAEMMI, U.K. Cleavage of structural proteins during the assembly of the head of bacteriophage T4. Nature, v.227, p.680-685, 1970. 
McGUIRE, T.C. et al. Caprine arthritis encephalitis lentivirus transmission and disease. Current Topics in Microbiology and Immunology., n. 160, p. 61-75, 1990.

OZYORUK, F. et al. Monoclonal antibodies to conformational epitopes of the surface glycoprotein of caprine arthritis-encephalitis virus: Potential application to competitive-inhibition enzyme-linked immunosorbent assay for detecting antibodies in goat sera. Clinical and Diagnostic Laboratory Immunology, n.1, p.44-51, 2001.

PINHEIRO, R.R. Virus da artrite encefalite caprina: desenvolvimento e padronização de ensaios imunoenzimáticos (ELISA e Dot-Blot) e estudo epidemiológico no Estado do Ceará. 2001. $115 \mathrm{f}$. Tese (Doutorado em Ciência Animal - Área Medicina Veterinária Preventiva e Epidemiologia) - Escola de Veterinária, Universidade Federal de Minas Gerais, Belo Horizonte, 2001.

REED, L.J.; MUENCH, H. A simple method of estimating fifty percent end points. American Journal of Hygiene, v.27, n.3, p.493-497, 1938.

REIS, J.K.P.; LEITE, R.C. An enzyme-linked immunosorbent assay (ELISA) test for the diagnosis of equine infectious anemia in Brazil. Preventive Veterinary Medicine, v.20, p.261-267, 1994.
SCHROEDER, B.A.; OLIVER, R.E.; CATHCART, A. The development and evolution of an ELISA for the detection of antibodies to caprine arthritis encephalitis vírus in goat sera. New Zealand Veterinary Journal, v.33, n.12, p.213-219, 1985.

SONIGO, P.; ALIZON, M.; STASKUS, K.; KLATZMANN, D.; COLE, S.; DANOS, O.; RETZEL, E.; TIOLLAIS, P.; HAASE, A.; WAIN-HOBSON, S. Nucleotide sequence of the visna lentivirus: relationship to the AIDS virus. Cell, v. 42 p. 369-382, 1985.

TORFASON, E.G.; GUDNADÓTTOR, M.; LOVE, A. Comparison of immunoblots with neutralizing and complement fixing antibodies in experimental and natural cases of Visna-Maedi. Archives of Virology, v.123, p.47-58, 1992.

VAREA, R.; MONLEO`N, E.; PACHECO, C.; LUJA`N, L.; BOLEA, R.; VARGAS, M.A.; VAN EYNDE, G.; SAMAN, E.; DICKSON, L.; HARKISS, G.; AMORENA, B.; BADIOLA, J.J. Early detection of maedi-visna (ovine progressive pneumonia) virus seroconversion in field sheep samples. Journal of Veterinary Diagnostic Investigation, v.13, p.301-307, 2001.

Recebido em 8/11/07

Aceito em 11/11/08 